Portland State University

PDXScholar

\title{
Teaching hearing-impaired children language through the use of musical rhythm
}

Naomi Anne Banducci

Portland State University

Follow this and additional works at: https://pdxscholar.library.pdx.edu/open_access_etds

Part of the Speech and Hearing Science Commons

Let us know how access to this document benefits you.

\section{Recommended Citation}

Banducci, Naomi Anne, "Teaching hearing-impaired children language through the use of musical rhythm" (1974). Dissertations and Theses. Paper 1282.

https://doi.org/10.15760/etd.1281

This Thesis is brought to you for free and open access. It has been accepted for inclusion in Dissertations and Theses by an authorized administrator of PDXScholar. Please contact us if we can make this document more accessible: pdxscholar@pdx.edu. 
TEACHING HEARING-IMPAIRED CHILDREN IAANGUAGE

THROUGH THE USE OF MUSICAL RHYTHM

by

NAOMI ANNE BANDUCCI

A substantial paper submitted in partial fulfillment of the requirements

for the degree of

\author{
MASTER OF SCIENCE IN SPEECH \\ with an emphasis in \\ SPEECH PATHOLOGY AND AUDIOLOGY
}

Portland State University

June 1974 
The substantial paper of NAOMI ANNE BANDUCCI has been approved as presented in May, 1974.

\footnotetext{
Joan McMahon, M.S., Advisor
} 


\section{ACKNOWLEDGMENTS}

My sincerest thanks go to the following faculty members:

Dr. James F. Maurer, without whose help, encouragement, and aid this paper would not have been written;

Dr. Robert H. English, for his insight into the subject; Mrs. Joan McMahon, for her editing. 
TABLE OF CONTENTS

PAGE

ACKNOWLEDGMENTS ............... 111

CHAPTER

I INTRODUCTION ............ 1

Purpose ............. 2

II METHODS AND AVENUES .......... 3

The Lowell Method ........ 3

The Carl Orff Method ........ 3

The Birkenshaw Method ....... 5

The Acoustic Method ....... 6

The Elizabeth May Method ....... 11

The Christopher Tree Method ..... 12

The Song Method ........ 13

The "Mod" Method .......... 14

The Ewing and Ewing Method ...... 15

The Kathleen J. Wojan Method ..... 18

The John Wahler Method ...... 19

The Tadoma Method ........ 20

SUMMARY ................. 22

BIBLIOGRAPHY ............. 25 
CHAPTER I

\section{INTRODUCTION}

The awareness of rhythm helps compensate hearing-impaired children for inadequate encoding of oral discourse, aiding in the improvement of their speech intelligibility. Rhythm, which 18 one of three aspects of prosody along with stress and intonation, can facilitate language growth in children by using avallable sensory avenues. Rhythm may be channeled to auditorally-deprived children through vision, vibration and residual nearing.

Learning the rhythm of music enables hearing-impaired chlldren to recognize visual patterns of purposive speech, its regularities in intonation, accents, emphasis, and breath pauses. They are able to develop correct respiration and learn through imitation to control the muscles of their tongue and other speech organs. The use of rhythm contributes toward correct modulation of the roice, reducing the tendency toward monotone speech.

While normal children acquire rhythm through the three sensory inputs of vision, tactile and audition, children with severe or profound deafness depend on visual and tactile sensory arenues. According to Davis and Silverman (1970), deaf children can be made aware of the many tactile and kinesthetic cues which can help them understand the nature of speech. 
Tactile stimuli are commonly defined as those pertaining to the organ or sense of touch, caused by or consisting of contact, while kinesthesis is considered the perception or consciousness of one's own muscular movement (Funk and Wagnalls New Practical Standard Dictionary, V, 1, 1949). Tactile and kinesthetic cues are of ten combined; however, other authors adrocate the use of kinesthetic avenues alone. Markell (1961) states that a steady rhythm or beat can be learned by awareness of the body functions. The beat of the heart or pulse as well as the process of respiration can be valuable indicators of rhythm for hearing-impaired children. Penn (1955) notes that deaf children often produce or breath too much air on exhalation. Tactile-kinesthetic cues often prove to be insufficient to serve as regulators of respiration (Penn, 1955).

PURPOSE

While several authors have indicated specific methods for teaching rhythm, there is no single, comprehensive source arailable which could serve as a teaching guide in this important area of aural rehabilitation. The current paper represents an initial attempt to fulfill this need. The purpose of this paper is to provide a survey of the different methods and avenues for teaching the rhythm of language to hearingimpaired children. 
CHAPTER II

\section{METHODS AND AVENUES}

\section{The Lowell Method}

Lowell (1960) has advocated that the initial step in the acquisition of rhythm for deaf children should concentrate on the visual and tactile avenues. Lowell instructed children in the rhythmic components of language by use of their sight, sight and residual hearing, and residual hearing alone to determine the "on" and "off" of music. He first drew attention to the placement of a needle on the phonograph record. This act was associated with the onset of music. The needle would then be remored, and this was associated with the termination of music. The use of a march with a strong beat encouraged children to use sight, residual hearing and body vibrations to tell the onset and termination of music. A march can be defined as a musical composition employing four equal beats to a measure (The Harvard Brief Dictionary of Music, 1960).

\section{The Carl Orff Nethod}

According to Orff (1956), the primary purpose of music education is the development of children's creative faculty which exhibits itself in the ability to improvise speech patterns. Orff's method was based on the concept that rhythm is the basic element in music. Rhythm was not taught mechanically 
or mathematically, or by counting beats; rather, it grew out of speech patterns. The rhythm contained in speaking and singing, poetry and music and movement, playing and dancing, are not yet separated in the world of children.

The Orff system incorporates kinesthetic and tactile avenues through music and movement. At the Toronto institution, speech rhythms are demonstrated through music and movement. By placing their hands on a vibrating drum, the children first experience rhythm. They are next encouraged to sense the vibration of repetitive sounds by sensing vibrations in the air and floor of the room. This aids the children in learning to walk, run, jump and skip to the drum beat.

Once the children acquire the rhythm imparted by the drum, the production of speech rhythms are taught by echo clapping. In this process, the children's teacher claps and the children clap in imitation of the teacher's pattern. For instance, the teacher might clap once for a word, or quickly sequence three claps for a short phrase. Following the teacher's model encourages the awareness of phrasing.

According to the Harvard Brief Dictionary of Music (1960), a phrase can be defined as a division or section of a musical line, somewhat comparable to a clause or a sentence in language. Phrasing is further implemented by use of the rondo, a piece of music having one principal subject to which a return is twice made after stated intervals. For example, the rondo "Bow Your Boat" might be used. The music encourages the children to be creative while providing a sense of security by returning 
to the beginning of the phrase. The children can pair the rondo with the volce, with movement alone, with the drum, or with percussive and melodic instruments. The orff Method permits the children to eventually make up their own rondo patterns on their own level.

Birkenshaw, a teacher at the Metropolitan Toronto School for the Deaf, aptly summarizes the effectiveness of the Carl Orff Method (1965, p. 352):

The Carl Orff Method, "Music for Children," can be effective in teaching deaf children movement, speech, and the joy of creating music. It helps them to become rhythmic and creative. The application of Carl Orff's method to the teaching of deaf children in the Metropolitan Toronto School for the Deaf has ben successful in developing confidence and poise, thereby contributing to their social development and natural grace.

The Birkenshaw Method

Birkenshaw applied the "Carl Orff Method" but went on to develop a technique which enabled children to sense music by means of various resonant properties of the human body. Inrestigations by Birkenshaw (1965) showed that parts of the body other than the ear respond to vibrations. In other words, different parts of the body have specific resonant frequencies. Auditorally-deprived children were administered highly amplifled sounds of different frequencies in a classroom setting and requested to identify the area of the body that responded. For example, Birkenshaw showed that with practice children could feel vibrations of high tones, approximately $1397 \mathrm{~Hz}$, in the chest. The low ranges from $32.7 \mathrm{~Hz}$. could be felt in 
the stomach cavity, feet, and legs. The xylophone, for instance, was felt in the stomach, and the low tympani sensed throughout the body. The use of various resonant properties of the body enabled the children to appreciate the rhythm of music, which in turn led to an understanding of the rhythm of language. Birkenshaw has indicated that music is not the end Itself but only a means of acquiring clear, understandable speech.

The Acoustic Method

According to Oyer (1966), Goldstein made the greatest contribution to teaching deaf children speech and language of any contemporary American. Goldstein (1939) defined his Acoustic Method as stimulation or education of the hearing mechanism and its associated sense-organs by sound vibrations, as applied either by volce or any sonorous instrument. Goldstein incorporated his Acoustic Method as a separate and distinct approach in teaching the deaf at the Central Institute for the Deaf in St. Louis, Missouri. His method encompassed the use of the voice and musical sounds delivered either through earphones or presented face to face. Also included was sound vibration, as sensed and differentiated by tactile impression in the interpretation of pitch, rhythm, accent, volume, and inflection, as well as the synthesis and construction of speech patterns. Accent can be defined as emphasis or stress on one tone (The Harvard Brief Dictionary of Music, 1960). 
The program for the children was divided into: 1) passive education, produced by musical instruments (piano, organ, harmonium) or sustained and amplified pure tones with the audiometer; 2) active education, which emphasized use of the rolce and was divided into analytic and synthetic acoustic exercises.

Within the program for passive education, all students at the Institute, regardless of the residium of hearing, were given dafly instrumental stimulation in addition to acoustic exercises for developing appreciation of musical sounds. Goldstein (1939) stated that students need to develop perception of tones within the range of speaking or singing. When a pup1l showed no perception for the important speech frequencies, constant application of sonorous vibrations outside of this range was used, and, then gradually, a perception for tones within the range of the speaking voice was approximated. Goldstein's passive method made use of musical interludes provided by the piano, a specially constructed accordlan, and an organ for the development of rhythm, pitch, accent, and rolume of tone. The organ and accordian were so constructed that their reeds emitted the same pitch either on compression or suction, and were capable of sustaining a specific tone of prolonged duration. Each of the reed instruments had been adapted for class instruction by connecting six pairs of tubes to the sound-chamber. The accordian designed for the children thus had a range of six octaves, extending from Contra $c$ to $c^{4}$ sharp. The reed used was of the blower type, 
selected because the tone produced evidenced greater volume with less effort than that of the suction-reed type. The instrument was supplied with three stops, which controlled three sets of reeds of different timbre. Timbre has been commonly defined as the quality of a musical or vocal sound, other than the pitch and intensity, enabling a listener to identify the unique source of production (The Oxford Universal Dictionary, 1955). Changing the combinations of these stops produced seven different timbres or qualities of tone. Goldstein felt that the employment of various timbres prepared the pupil for perception and differentiation of various qualities of the human voice. The author belleved that in the beginning of the program it was necessary to sustain the tone for ten seconds in an effort to produce stimulation of the hearing mechanism. When students could differentiate between musical timbres, they were ready to be introduced to the active part of the Acoustic Method which was divided into the analytic and synthetic approaches.

In the analytic approach the first step consisted of having the children listen to the teacher's voice in the production of rowels and attempt to discriminate between them. Goldstein considered the following vowels elementary: 1) [a] as in father, 2) [i] as in eel, 3) [u] as in pool, and, 4) $[e]$ as in ale. The vowels were presented at different pitches (high and low), and when children could correctly interpret the differences by responding rocally, diphthongs were introduced. Consonant and syllable drills followed. 
Each consonant then was combined with the various vowels. For example, in the first step of the syllable drill, the consonants $[S]$ and $[s]$ were placed between two vowels. Goldstein contended that the consonant was more easily heard in that position. The consonant was then placed at the beginning or end of a word. Goldstein stated consonant differentiation was emphasized by prolonging the sound, then by placing it first in the inftial and the medial position of the four vowels. The consonants $[f-k-t-r]$ and $[b]$ were then incorporated into the same systematic exercises. Phrases were constructed of previously practiced words and their combinations. Sentences of single syllable words containing these sound elements were then introduced.

According to Goldstein, once children could differentiate Individual vowels or consonants as well as phrases and single syllable sentences, they were ready for synthetic exercises. The author felt that the auditory comprehension of speech and language was developed through the synthetic segment of the acoustic program. Synthetic exercises began with words made up of vowel and consonant combinations, previously worked on during the analytic exercises. Goldstein classified one-syllable words according to their pitch or sonorous characterist1cs. Two syllable words of unequal pitch were then worked on by the children. Once the children were ready for phrases composed of the previously practiced words, the teacher presented these statements at varying degrees of intensity. The children echoically responded to these phrases, as the teacher 
first prolonged each syllable and then gradually approximated normal duration. The same phrase or sentence was taught with different rhythms, accents, and tempos.

The author believed that application of the Acoustic Method may be better understood by an analysis of a sample case. A.L., a female, age eleven years, was admitted to the Central Institute for the Deaf in St. Louis, Missouri, at three years of age. The first steps of the Acoustic Method were given to determine A.L.'s ability to differentiate vowel sounds. Goldstein stated that he deviated from his usual program by having A.I. proceed with practice on words and phrases which she could lip-read before accurate differentiation of vowel sounds was achieved. The teacher's words and phrases were spoken while A.L. used an amplifier and earphones. The teacher stood in front of the pupil, thereby taking advantage of the student's lip-reading ability. The instructor carefully accentuated and articulated each word. Each syllable was emphasized by the teacher tapping on the pupil's shoulder. Repetition was stressed. The exercises were presented by the teacher without visual cues, thereby eliminating A.L.'s lipreading ability. According to Goldstein, the pupil was able to differentiate all phrases practiced in any given order at the end of the first lesson.

When the children completed the active program, they had progressed through the various stages of the Acoustic Method. Upon completion of the active program, the children were expected to have acquired the following skills: 1) to 
form the connecting link between instrumental and vocal stimulation by the use of singly-sustained vowels of varlous pitches, and, 2) to acquire the ability to identify vowels and consonants when heard in any combination. In summarizing his philosophy towards training profoundly deaf children, Goldstein (1939, p. 170) said:

It is a significant observation that over thirty per cent of all congenitally deaf children have some residum of hearing. In some cases it is of so limited a degree that it cannot be fully and practically utilized in training by the Acoustic Method; in a larger group it remains latent because of insufficient stimulation; in all cases it should be given a reasonably long try-out, for these auditory remnants are peculiarly sensitive to stimulation and re-education and in a large percentage of cases the perserverence and resourcefulness of the teacher will be rewarded by surprisingly good practical results.

The Elizabeth May Method

May (1961), a music teacher in the Santa Monica elementary schools, had two goals in mind when she presented music to a group of deaf and hard-of-hearing children in Madison Elementary School. She believed in: 1) teaching language through exposing the children to a rich, cultural background, which they were usually denied, and, 2) explaining techniques by which specific instruments are played.

The children at Madison were invited to inspect an organ at the University of California at Los Angeles. The children were prepared for their trip by being shown pictures of organs and by investigation of an up-right piano. Upon arrival at the University, the children were allowed to climb to the 
organ loft while playing of the organ was in progress. May (1961) stated that unfortunately since this activity required physical skills, children with motor difficulties were not able to participate. Those allowed to attend were delighted to receive kinesthetic cues which aided in teaching them the rhythm of music.

May also invited individual members of the University orchestra to bring and play their instruments for the children at the Madison School. During these sessions the children were allowed to touch the instruments, to blow them, or hit them, or pluck them, depending on what was appropriate. According to May, allowing the children to experiment in feeling and playing the instruments brought them to a closer realization of the rhythm of music.

The Christopher Tree Method

The principal of the Mary E. Bennett School for the Deaf in Los Angeles, California, Evelyn M. Stahem (1967), introduced musical rhythm to deaf children by inviting a musiclan capable of playing one hundred instruments to play a concert.

Christopher Tree, the musician, named his performance the Spontaneous Sound Symphonic Concert. Many of the instruments he used were from the countries of China, India, Tibet, Switzerland, Garmany, and Japan. Tree brought gongs, bells, chimes, reeds, flutes, strings, cymbals, tympani, tom-toms, and a Tibetan Temple Horn. During the concert, the artist 
created the mood of the moment by reacting to the mood of the audience.

Children from the sixth grade down to nursery school level responded to the music with feelings which ran from joy and delight to alarm as the beat of the tympani reverberated throughout the auditorium. Some children laughed or covered their ears with their hands according to the varying moods of the music and their individual reactions. The children not only responded to the feel and sound of the music, but also were intrigued by the movements of Tree as he glided from instrument to instrument, rhythmically swinging a padded mallet or stopping to play horns, strings, tom-toms, and flutes. Apparently the visual component of the program contributed greatIy to the impact of the experience. Some children could hear specific instruments, the six-foot Tibetan Horn being the one most often cited. Tree's concert was played without the use of written score. By introducing children to the spontaneity in playing instruments, teachers emphasized the spontaneity necessary for correct speech rhythms.

\section{The Song Method}

Acting on the hypothesis that special songs need to be written that meet the language needs of deafened children, Smith (1956) devised songs containing grammatical articles and pronouns. Smith noted three major criteria for song, which she posed as questions for the teachers of the deaf: 1) is the song meaningful to the children?, 2) is the 
rocabulary within the scope of their speech abilities?, and, 3) is the song of interest to the children? Before the songs were presented to the class, the teacher encouraged the children to talk about what they had worn or brought to school and incorporated these items into songs. Any color referent mentioned also was included. All concepts were explained by the teacher and understood by the students before the children recited them.

Based on Smith's program, teachers of the deaf could devise songs for auditorially-deprived children that would facilitate the use of complete sentences, containing articles and pronouns. Smith stated that the Song Method stimulated language development and provided material for auditory training.

\section{The "Mod" Method}

Hogan, Beirne, and Butler (1968) reported on a program they named the "Mod" Method at a School for Deaf Children in New York City. Mrs. Lila Heirbrun, a teacher at the school, introduced music to deafened children through a guitar-centered program using a "Mod" approach. The teacher used both traditional folk music and music and lyrics written by some of the teachers at the school. Mrs. Heirbrun belleved that the guitar has the advantage over the traditional piano exercises because it can be easily transported, and the player can sit on the same level as the children. According to Heirbrun, the children could watch the guitarist's fingers as she strummed. They could place their hands on the guitar 
as they sang, thereby gaining a sense of participation and kinesthetic feedback. During the elght years that the program had been in effect, children fitted with hearing aids and within easy lip-reading distance of the player had improved their speech reception and expression, which Heirbrun attributed to the "Mod" Method.

\section{The Ewing and Ewing Method}

The Ewings (1954) aimed their method at improving the quality and the quantity of deaf children's speech. The authors believed that both aurally-deprived and hearing children's speech and language development depended upon a "talking-environment" in the home, which encouraged a free-flow of conversation between parents and children. Working on the hypothesis that deaf children need an environment that encouraged use of normal language patterns, the Ewings devised a school program that stimulated spontaneity. The authors felt that spontaneity facilitated the use of the natural rhythm of language by auditorially-deprived children. The authors contended that when deaf children use natural language rhythms, their speech becomes more intelligible.

The authors cited several factors contributing to faulty rhythm in deafened children. Among the factors they included were: 1) the use of isolated words instead of phrases and sentences, 2) poor ability in pronouncing and combining consonants, and, 3) poor control of breath and volce.

The Ewings reported on dual methods for developing rhythm 
in the speech of deaf pupils. In the first approach, appreciation of rhythmic patterns was established through the use of percussion instruments and a piano. Residual hearing was used by combining the musical sounds sensed with the body movements of clapping, stepping and dancing, running, waving, etc.

The second method introduced young pupils to the experience of musical vibration and rhythm through the sense of touch. Percussion instruments and the piano were used. For children possessing residual hearing, appreciation of rhythm was always associated with auditory training. The authors felt that this method was markedly successful with children at the nursery and infant stages.

The authors believed that the two methods they cited emphasized developing an appreciation of rhythm for its own sake. The Ewings combined the two methods, emphasizing the use of sonorous instruments, touch and movement, and residual hearing in a classroom setting. In classes for auditorally-deprived children, the Ewings considered that it was the teacher's responsibility to devise rhythm lessons that interest pupils in developing rhythmical speech. Teachers employed short and long term goals in their lessons, which included auditory training, with the help of an aid. Auditory training was combined with rhythm training by using residual hearing and lipreading in conversational as well as formal oral lessons. The teacher incorporated teaching devises that encouraged the use of spoken, complete, simple sentences which extended the children's vocabulary and implemented the use of rhythmical 
speech.

Lesson planning for children provided time set aside for group and individual work. Individual lessons emphasized phonetic analysis of all sounds in words, phrases and sentences which were a part of the children's lip-reading ability. The group sessions often used the same sentences employed in the individual lessons. The authors stated that when the children were able to automatically repeat words, they were able to concentrate on the rhythm necessary to convey the meaning of a sentence. The rhythmic patterns of sentences were first combined with body movements, and then the sequences were practiced mentally before they were pronounced aloud. If the method proved successful, after four years of training with the Ewing's method, children of seven years of age should correctly produce all consonants, vowels, and diphthongs. Exposure to the method did not guarantee automatic speech skills at this point.

The Ewings felt that deafened children needed many years of training. The authors believed that upon completion of their program pupils should have speech and language abilities similar to children with normal hearing, and should be able to duplicate the following aspects which they considered necessary for rhythmically pleasant and intelligible speech. The Ewings primary aspects for normal speech were: 1) the use and management of a natural speaking volce to the loudness needs of a listener under different acoustic conditions, 2) control of pitch to ensure natural intonation according to the 
emotional content of the words being spoken, 3) clear pronunciation of the vowels, 4) accurate articulation of the consonants, and 5) capacity to speak rhythmically.

The Kathleen J. Wojan Method

Wojan (1955), a teacher at the Lexington School for the Deaf, New York City, used Eurthmics, which was a system developed for promoting harmony between mind and body, to assure rhythmic motion of the limbs. She felt that her method was unique in that it was based on Lenneberg's theory of parallel speech and motor development. The author believed that her approach of combining body movements with speech facilitated language development in deafened children.

At the Lexington School, children attended rhythm classes twice a week for fifteen minutes. The children spent ten minutes at the piano and five minutes of game and body work. Children attending the nursery school section stood on benches around a piano placing their hands on its top, feeling the musical vibrations being played. The children listened to the music with their heads lowered and raised their heads as the music stopped.

Although children at the nursery school level were only expected to react to vibrations by raising and lowering their heads, children in the pre-school and primary grades were expected to sing songs which incorporated body movements. At first, the songs and physical activities were simple, becoming more complex as the children's abilities improved. 
Pre-school and primary pupils spent one-half hour twice a week in Wojan's Eurthmics system. The children's time was divided between work on vibrations, song, preparatory work for body coordination, rhythmic body exercises, and observation exercises.

Children above the primary grades received one lesson a week. Wojan grouped the children and worked with them at the piano. The pupils learned to clap to the rhythm of the music played. In addition to clapping rhythms, the children learned to dance to various rhythms. The children learned tap dance and social dance to various rhythms, by having them memorize the dance patterns and sequences involved.

\section{The John Wahler Method}

John Wahler (1966) lost all hearing sensitivity in his right ear and ninety percent in his left ear at the age of fourteen. This occurred in 1949, at which time he was fitted with a hearing-aid which was initially unsuccessful. With the passing of time and experimenting with his aid, he began to develop his residual hearing and was able to identify once familiar melodies. However, many musical and speech sounds remained incomprehensible.

In an effort to pursue his auditory training, he bought a record player and reissues of records he had enjoyed before he became deafened. He played the records repeatedly until a trace of the melody emerged. He continued playing a record until the recorded selection sounded as he remembered. 
After Mr. Wahler repeated the melodies he heard on the record several times, he was able to hum or sing them correctly. After working on melodies familiar to him, he found that he could follow most arrangements of songs he had never heard.

The author became interested in increasing his understanding of speech. He worked with recordings of spoken poetry, following a script as the readings progressed. He also used a portable transistor radio, adapting the earphone to his hearing-aid earphone. His job as a draftsman allowed him to listen to the radio several hours a day. He memorized the commercials that were constantly repeated throughout the day.

Mr. Wahler found many benefits from his auditory training. By $1966 \mathrm{Mr}$. Wahler could understand many news and weather reports, but still found conversational speech difficult.

\section{The Tadoma Method}

Vibration was first used as a method for teaching the deaf in Norway in the 19th century. Sophia Alcorn of the United States rediscovered the method when she was assigned to teach two deaf-blind children speech. She named the method by combining the boy's first name, Tad, and the girl's first name, Oma.

The Tadoma, or vibration, method was designed so that deaf-blind, or deafened children, could feel the muscular movements and the vibrations of sounds. Alcorn noted that auditorally-deprived children seldom had been exposed formally to vibration. For this reason, the author, Rose $M$. 
Vivian, a subsequent investigator of the Tadoma Method, suggested that children be introduced to vibrations by first calling their attention to the sounds and vibrations made by planes, trucks, feet stomping on a wooden floor, or playing of musical instruments. The teacher then placed the child's hands on the teacher's head, chest, or back, as she spoke or hummed. Next the child's hands were placed on the teacher's face so that one hand had the thumb on the lips of the speaker and the fingers laid lightly on the cheek. The fingers were spread from the cheekbone down to the jawbone just below the ear. The little finger laid on the hollow just below the thyroid cartilage. The other hand was similarly placed except that the child's thumb was placed at the corner of the teacher's mouth. Later in the method, the child could choose whether he wanted to use his hands simultaneously or alternately.

The teacher began teaching basic speech rhythm skills by vocally producing sounds while the deaf child's hands were on the teacher's face in the prescribed manner. The teacher started and stopped sounds as well as varying the intensities and pitches. The piano also was used to play the same type of exercises. During this part of the method, the emphasis was on the teacher's producing the sounds and the child's feeling the muscular movements necessary for production.

The child was prepared for vocal imitation by first reproducing the teacher's gross body movements of walking, run- 
ning, jumping, stopping and starting, and then fine motor movements of head motions, facial motions, mouth and cheek motions, and tongue motions. Once the child was proficient in imitating the teacher's fine motor movements, the teacher began speech sounds using moderate volume and pitch, and flexible lip movements. The child first repeated vowel sounds and then consonants. As each sound was introduced by vibration, it was also presented to the child in braille or print. The teacher checked the child as he produced speech sounds to make sure he had used correct tongue placement and mouth position for each sound.

Vivian believed that use of the Tadoma Method supplied the child with a comparison of vibrations and muscular movements. The child was able to imitate single speech elements or whole words by placing one hand on the speaker's face and his other hand on his own face, thereby comparing the vibrations and muscular movements needed for rhythmical speech.

\section{SUMMARY}

Rhythm has been employed in many ways by investigators to teach the pattern of language to auditorally-deprived chlldren. Many experimentors combined residual hearing, visual, tactile, and kinesthetic cues in varying ways to instruct deafened chlldren to approximate rhythmic speech.

Various authors felt that music is a valuable tool in teaching the normal rhythm of language patterns to auditorally-deprived children. Orff (1965) stated that rhythm was 
the basic element in music. He combined tactile and kinesthetic cues to teach rhythm. He felt that speech rhythms could be demonstrated through music and movement. Goldstein (1939) noted that a rhythm program should emphasize auditory trainIng by use of musical stimulation to the hearing mechanism. Birkenshaw (1965) employed the use of natural resonant properties of the human body as a means to appreciate the rhythm of language. Although these many investigators used diverse approaches, they all achieved some success by emphasizing the rhythm of language. 
B I B L I O G R A P H Y 


\section{REFERENCES CITED}

Apel, Willi, and Daniel, Ralph T. The Harvard Brief Dictionary of Music. New York: Amsco Music Publishing Co., $(1960)$.

Birkenshaw, Lois, Teaching music to deaf children. Volta Review, Vol. 67, No. 5, 352-358, 387 (1965).

Ewing, Irene R. and Ewing, Alexander. Speech and the Deaf Child. Washington, D.C.: Manchester University Press, The Volta Bureau (1954)

Funk and Wagnalls New Practical Standard Dictionary. Charles Earle Funk (Ed.). New York: Funk and Wagnalls Company (1950).

Hearing and Deafness. Hallowell Davis and Richard Silverman (Eds.). New York: Holt, Rinehart and Winston (1970).

Gilmore, Elizabeth M., Rhythm, language, and the deaf child. Volta Review, Vol. 68, No. $2,160-165$ (1966).

Goldstein, Max A. The Acoustic Method. St. Louis, Mo.: The Laryngoscope Press (1939).

Hogan, Loretta C., Beirne, Patricia and Butler, Susan A., A music program for young deaf children---a "Mod approach." Volta Review, Vol. 70, No. 7, 561-563 (1968).

Lowell, Edgar L. and Stoner, Marguerite. Play It By Ear! Wolfer Publishing Company for the John Tracy Clinic (1960).

Markell, Alan, Teaching deaf children to dance. Volta Review, Vol. 63, No. 4, 176-177 (1961).

May, Elizabeth, Music for deaf children to dance. Volta Review, Vol. 63, No. 4, 220-223, 246 (1961).

Orff, Carl. Music for Children. Mainz: B. Schott's sonne $(1956)$.

Oxford Universal Dictionary. The. C.T. Onions (Ed.). New York: Oxford University Press (1955).

Oyer, Herbert J. Auditory Communication for the Hard of Hearing. Englewood Cliff's, New Jersey: Prentice-Hall $(1966)$. 
26

Penn, J.P., Voice and speech patterns of the hard of hearing. Act Óto-Laryngologica Supplementum 124 (1955).

Smith, Meredith Jane, Songs for the primary grades. Volta Review, Vol. 58-59, No. 6, 253-255 (1956).

Stahlem, Evelyn M., The feel of music. Volta Review. Vol. 69, No. 7, 368-369 (1967).

Vivian, Rose M., The Tadoma method: a tactual approach to speech and speech reading. Volta Review, Vol. 68, No. 10, 733-737 (1966).

Wahler, John, An odyssey in deafness. Volta Review, Vol. 68, No. 2, 154-158 (1966). Wo jan, Kathleen, Eurythmics. Volta Review, Vol. 57 , No. 5 ,
253-254 (1955). 